\title{
INSIGHTS INTO THE ROLE OF MORUS ALBA IN REVERSING OBESITY-ASSOCIATED HEPATIC STEATOSIS AND RELATED METABOLIC DISORDER IN RATS
}

\author{
FATEHYA M METWALLY ${ }^{1}$, HANAA H AHMED ${ }^{2 *}$, HEND RASHAD ${ }^{1}$, ASMAA M ZAAZAA ${ }^{3}$
}

${ }^{1}$ Department of Environmental and Occupational Medicine, National Research Centre, Giza, Egypt. ${ }^{2}$ Department of Hormones, National Research Centre, Giza, Egypt. ${ }^{3}$ Department of Zoology, Faculty of Women for Arts, Science and Education, Ain Shams University, Cairo, Egypt. Email: hanaaomr@yahoo.com

Received: 24 June 2016, Revised and Accepted: 02 July 2016

\section{ABSTRACT}

Objective: The goal of the present study was to examine the viability of Morus alba (M. alba) ethanolic extract in repression of obesity-associated hepatic steatosis and related metabolic disorder; dyslipidemia, hyperinsulinemia, and glycemic status.

Methods: Adult female albino rats were randomly assigned into four groups, eight rats each as follows: Group (1) control group received standard rodent diet for 24 weeks. The other three groups administered high cholesterol diet for 12 weeks and served as obese group, M. alba-treated group, and simvastatin-treated group.

Results: The current results showed an increment in thoracic circumference (TCX) and abdominal circumferences (AC) as well as body mass index (BMI) in obese group. In addition, dyslipidemia, hyperinsulinemia, hyperglycemia, and insulin resistance have been elucidated in obese group. Moreover, hepatic malondialdehyde (MDA), nitric oxide (NO), serum alanine aminotransferase (ALT), aspartate aminotransferase (AST), and bilirubin values were significantly increased in obese groups versus control group. On the other hand, administration of ethanolic extract of Morus alba or simvastatin could significantly lessen BMI and in addition to improve dyslipidemia in obese group. Glucose, insulin levels, and insulin resistance value in serum samples demonstrated a significant reduction in obese group upon treatment with M. alba ethanolic extract or simvastatin. Furthermore, noticeable depletion in hepatic MDA, NO contents, serum ALT, AST activities, and serum bilirubin level was recorded as a result of treatment with either ethanolic extract of M. alba or simvastatin. Histopathological examination of liver tissue showed ballooning degeneration in the hepatocytes (hepatic steatosis) associated with inflammatory cells penetration in portal zone in obese group. Meanwhile, the treatment of obese groups with ethanolic extract of M. alba or simvastatin was found to restore the structural organization of the liver.

Conclusion: The present findings provide a novel aspect for understanding of the role of M. alba against obesity-associated liver diseases and related metabolic disorder. The mechanisms underlying these effects seem to depend on the hypolipidemic potential, anti-inflammatory property, and antioxidant activity of its phytochemicals.

Keywords: Obesity, Morus alba, Dyslipidemia, Hyperinsulinemia, Hyperglycemia, Hepatic steatosis.

(C) 2016 The Authors. Published by Innovare Academic Sciences Pvt Ltd. This is an open access article under the CC BY license (http://creativecommons. org/licenses/by/4. 0/) DOI: http://dx.doi.org/10.22159/ajpcr.2016.v9s2.13674

\section{INTRODUCTION}

Liver is one of the largest organs in the human body that regulates homeostasis of the body [1], metabolic [2], and excretory functions [3] It involves almost all the biochemical pathways of growth, fight against disease, nutrient supply, and reproduction [4]

Obesity is a complicated multifactorial metabolic disorder induced due to an imbalance between energy intake and expenditure that may have genetic and/or behavioral causes including the amount and nature of food intake and way of life [5]. Obesity is identified by boosted body weight and abnormal expansion of fat tissue with undue fat deposition, associated with severe deregulation of the endocrine capacity of fatty tissue [6]. It is a condition linked with a bunch of chronic and progressive diseases that have various aspects of metabolic disorder including diabetes, hyperinsulinemia and insulin resistance, dyslipidemia, cardiovascular defects, hepatic and renal pathologies, inflammation, and cancer $[7,8]$.

Hepatic steatosis or fatty liver is mainly due to obesity and metabolic disorder. Hepatic steatosis is recognized by infiltrated fats and accumulated lipids, especially triglycerides in the liver, associated with enhanced liver/body weight proportion [9].

Sustainable agents from natural sources could act as applicable alternatives to currently used synthetic drugs in the treatment of obesity-related disorders. This may be attributed to the toxic adverse effects of these synthetic drugs and their expensive prices which make them not easily attainable to many patients in developing countries like Egypt. Phytochemicals in most of the medicinal plants could protect against free radicals formation, degenerative disorders, and lifestyle-related diseases. Morus alba (Moraceae) has been reported to have hypolipidemic effects in diabetic patients and hyperlipidemic rodents. $M$. alba has been found to possess a unique nutritional profile containing proteins, phenolics, flavonoids, and anthocyanins that enhance its effect as natural potent tonic [10]. The active ingredients of $M$. alba extract particularly quercetin, rutin, and isoquercitrin capture free radicals revealing efficient antioxidant effect. Presence of prenylated flavonoids further confirms its antioxidant claims [11].

The current study was tailored to investigate the effectiveness of ethanolic extract of $M$. alba on obesity-related hepatic steatosis and associated metabolic disorder; dyslipidemia, hyperinsulinemia, and insulin resistance in a rat model of obesity

\section{METHODS}

\section{Materials}

Chemicals and drugs

Cholesterol was purchased from Sigma Chemical Co., USA. Simvastatin was purchased from Commercial Market, Cairo, Egypt. It is manufactured by MSD B.V Co., UAE. All other reagents, solvents, and 
chemicals used for analysis met the quality criteria in accordance with the International Standards.

\section{Plant preparation and extraction procedures}

Air-dried aerial parts of M. alba Lam. were purchased from a local market in Cairo, Egypt, and the plant was identified by a botanist of the herbarium at the Botany Department, Faculty of Science, Cairo University, Giza, Egypt.

Dried aerial parts of $M$. alba $(2 \mathrm{~kg})$ were pulverized into fine powder using a stainless steel blender and passed through a mesh opening of $35 \mathrm{~mm}$ sieve. Then, the powder was extracted by cold percolation with $95 \%$ ethanol $(3 \times 4 \mathrm{~L})$ till exhaustion. Afterward, the ethanol extract was concentrated under reduced pressure to give $250 \mathrm{~g}$ of brown residue. The residue was kept in a refrigerator till used in the biological assay.

\section{Biological assay}

\section{Animals and treatments}

All experiments involving animals and tissue samples were conducted in accordance with the principles and guidelines for the care and use of laboratory animals in the National Institute of Health, USA. This study was approved by the Ethical Committee for Animal Experimentation, National Research Centre, Egypt.

A total of 32 adult female albino rats of Wistar strain weighing $130 \pm 10 \mathrm{~g}$ at 90 days of age were enrolled in the present study. The animals were obtained from the Animal House Colony of the National Research Centre, Cairo, Egypt. The animals were housed throughout the experiment (8 rats/cage) in polypropylene cages under specific pathogen-free conditions with controlled illumination (12 hrs light/12 hrs dark cycle), relative humidity $(30-50 \%)$, and temperature $\left(18-22^{\circ} \mathrm{C}\right)$. Animals were fed with standard laboratory rat diet and water provided ad libitum. Animals were allowed to adapt to their environment for 2 weeks before the commencement of the experiment.

After the acclimatization period, eight rats were fed with standard laboratory rat diet containing $26.5 \%$ protein, $3.8 \%$ fat, $40 \%$ carbohydrate, and $4.5 \%$ crude fiber in $100 \mathrm{~g}$ of chow during 24 weeks of the experimental period and served as incline control group. The other 24 rats were fed with high-cholesterol diet (HCD) containing 19.93\% protein, $15 \%$ cholesterol, $57.50 \%$ carbohydrate, and $2.81 \%$ dietary fiber in $100 \mathrm{~g}$ of chow (modified method of Soliman et al. [12]) for 12 weeks. The dietary ingredients were homogenized in distilled water and dried in an incubator at $60^{\circ} \mathrm{C}$ for $24 \mathrm{hrs}$ and cut into small equal-sized pieces (pellets). HCD was given fresh each day as dry pellets; therefore, there was no spillage [13]. These rats were further assigned into three groups: Obese group in which the rats were fed with HCD for 12 weeks, then fed with standard laboratory rat diet for other 12 weeks; M. albatreated group in which the rats were fed with HCD for 12 weeks, then fed with standard laboratory rat diet with simultaneous administration of $M$. alba ethanolic extract by intragastric gavage tube in a dose of $250 \mathrm{mg} / \mathrm{kg}$ b.wt. according to Sarikaphuti et al. [14] for 12 weeks; and simvastatin-treated group in which the rats were fed with HCD for 12 weeks, then fed with standard laboratory rat diet with simultaneous administration of antihypercholesterolemic drug (simvastatin) by intragastric gavage tube in a daily dose of $5 \mathrm{mg} / \mathrm{kg}$ b.wt. according to Mbikay [15] for 12 weeks.

\section{Methods}

\section{Anthropometrical measurements}

After animal treatment was over, rats in the different studied groups were fasted overnight (12-14 hrs), and the abdominal circumference (AC) (immediately anterior to the forefoot), thoracic circumference (TC) (immediately behind the foreleg), body length (nose-to-anus or nose-anus length), and body weight were measured following light ether anesthesia. Body length and body weight were used to determine body mass index (BMI) [13]
BMI $\left(\mathrm{g} / \mathrm{cm}^{2}\right)=$ Body weight $(\mathrm{g}) /$ Length ${ }^{2}\left(\mathrm{~cm}^{2}\right)$

\section{Sample collection}

After recording the anthropometric measurements, orbital blood samples were obtained from the retro-orbital venous plexus using microcapillaries. The blood samples were collected in a clean, dry centrifuge tubes and allowed to clot to obtain sera. Serum samples were separated by centrifugation at $1800 \times g$ for 10 minutes at $4^{\circ} \mathrm{C}$. Aliquots of serum samples were frozen and stored at $-20^{\circ} \mathrm{C}$ pending further analysis. Following blood collections, animals were sacrificed by cervical dislocation, and a midline abdominal incision was performed, and whole liver of each animal was rapidly dissected out, thoroughly washed with ice-cold isotonic saline, blotted dry and then weighed. Each liver was divided into two portions. One portion was immediately homogenized to give $10 \%(\mathrm{w} / \mathrm{v})$ homogenate in ice-cold medium containing phosphate buffer (pH: 7.4). The homogenate was centrifuged at $1800 \times g$ for 10 minutes at $4^{\circ} \mathrm{C}$. The supernatant $(10 \%)$ was separated and stored at $-20^{\circ} \mathrm{C}$ for the determination of malondialdehyde (MDA) and nitric oxide (NO) contents. The second portion of the liver was fixed in $10 \%$ formalin saline for histopathological investigation.

\section{Biochemical determinations}

Serum total cholesterol, triglycerides, high-density lipoprotein (HDL), and serum glucose levels were assayed by colorimetric methods using Reactivos GPL kits (Barcelona, Espana) according to Meiattini [16], Bucolo and David [17], Naito [18], and Trinder [19], respectively. Serum low-density lipoprotein (LDL) level was quantified by colorimetric method using Centronic (Gmbh) kit (Wartenberg, Germany) according to Wieland and Seidel [20]. Serum insulin was estimated by enzyme-linked immunosorbent assay using Immunospec Corporation kit (USA) according to the method of Eastham [21]. Hepatic MDA content was determined by a colorimetric method using Biodiagnostic kit (Egypt) following the method of Satoh [22]. Hepatic NO content was estimated by colorimetric method using Biodiagnostic kit (Egypt) according to the method of Montgoery and Dymock [23]. Serum alanine aminotransferase (ALT) and aspartate aminotransferase (AST) activity were determined by the colorimetric method using Salucea kit (The Netherlands) according to the method described by Young [24]. Serum total bilirubin was estimated by a colorimetric method using Biodiagnostic kit (Egypt) according to the method described by Walterv and Gerade [25]. Hepatic total protein level was determined by the colorimetric method of Lowry et al. [26]. Assessment-insulin resistant (homeostatic model assessment-insulin resistance [HOMAIR]) was calculated using the following formula;

HOMA-IR $=[$ Fasting glucose $(\mathrm{mg} / \mathrm{dL}) \times$ Fasting insulin $(\mu \mathrm{IU} / \mathrm{mL})] / 405$

According to Matthews et al. [27].

\section{Histopathological investigation}

After fixation of liver specimens in formalin saline $(10 \%)$ for 24 hrs, washing in tap water was done, and then the liver samples were subjected to serial dilutions of alcohol (methyl, ethyl, and absolute ethyl) for dehydration. Afterward, liver specimens were cleared in xylene and embedded in paraffin wax at $56^{\circ}$ in a hot air oven for 24 hrs. Paraffin wax tissue blocks were submitted for sectioning at $4 \mu \mathrm{m}$ by Sledge microtome. The obtained tissue sections were collected on glass slides, deparaffinized, and stained with hematoxylin and eosin [28]. After staining, the slides were viewed with an Olympus $\mathrm{CH}$ (Japan) light microscope [29].

\section{Statistical analysis}

In the present study, all results were expressed as mean \pm standard error of the mean. Statistical Package for the Social Sciences program, version 14.0 was used to compare significance between each two groups. Difference was considered statistically significant when $\mathrm{p}<0.05$. Percentage difference representing the percent of variation with 
respect to corresponding control group was calculated according to the following formula:

$\%$ Difference $=($ Treated value - control value $) /$ control value $) \times 100$

\section{RESULTS}

Anthropometrical measurements

The present study showed a significant increment $(\mathrm{p}<0.05)$ in $\mathrm{TC}$ (31.97\%), AC (27.18\%), and BMI (38.03\%) of obese group with respect to control group. Meanwhile, obese group treated with ethanolic extract of M. alba or simvastatin led to significant reduction $(\mathrm{p}<0.05)$ in TC $(-16.96 \%$ and $-19.13 \%$, respectively), AC $(-18.40 \%$ and $-19.83 \%$, respectively), and BMI ( $-23.78 \%$ and $-24.59 \%$, respectively) as compared to obese group (Table 1). Interestingly, no significant alterations were observed $(p>0.05)$ between the obese group treated with ethanolic extract of M. alba and that received simvastatin as for the anthropometric estimations (Table 1)

\section{Biochemical determinations}

Data in Table 2 illustrated the effect of ethanolic extract of $M$. alba administration on lipid profile of obese rats. A significant increase $(\mathrm{p}<0.05)$ in serum cholesterol, LDL, and triglycerides levels $(104.18 \%$, $90.16 \%$, and $37.29 \%$ individually) was detected in obese group versus control group. Meanwhile, serum HDL level recorded marked reduction $(p<0.05)$ in obese group $(-47.24 \%)$ versus control group. On the other hand, obese group treated with ethanolic extract of M. alba or simvastatin exhibited a significant reduction $(\mathrm{p}<0.05)$ in serum cholesterol $(-28.65 \%$ and $-38.81 \%$ separately), LDL $(-24.76 \%$ and $-38.05 \%$ individually), and triglycerides $(-21.18 \%$ and $-32.53 \%$ individually)

Table 1: Effect of M. alba ethanolic extract on anthropometric estimations in obese rats

\begin{tabular}{|c|c|c|c|}
\hline \multirow[t]{2}{*}{ Groups } & \multicolumn{3}{|l|}{ Parameters } \\
\hline & TC (cm) & $\mathrm{AC}(\mathrm{cm})$ & BMI $\left(\mathrm{g} / \mathrm{cm}^{2}\right)$ \\
\hline Control group & $12.20 \pm 0.35$ & $15.34 \pm 0.18$ & $0.710 \pm 0.021$ \\
\hline Obese group (Ob) & $\begin{array}{l}16.10 \pm 0.27^{a} \\
(31.97 \%)\end{array}$ & $\begin{array}{l}19.51 \pm 0.31^{\mathrm{a}} \\
(27.18 \%)\end{array}$ & $\begin{array}{l}0.980 \pm 0.015^{a} \\
(38.03 \%)\end{array}$ \\
\hline $\mathrm{Ob}+M \cdot a l b a$ & $\begin{array}{l}13.37 \pm 0.26^{b} \\
(-16.96 \%)\end{array}$ & $\begin{array}{l}15.92 \pm 0.26^{b} \\
(-18.40 \%)\end{array}$ & $\begin{array}{l}0.747 \pm 0.021^{b} \\
(-23.78 \%)\end{array}$ \\
\hline $\mathrm{Ob}+\mathrm{Sim}$ & $\begin{array}{l}13.02 \pm 0.23^{b} \\
(-19.13 \%)\end{array}$ & $\begin{array}{l}15.64 \pm 0.32^{\mathrm{b}} \\
(-19.83 \%)\end{array}$ & $\begin{array}{l}0.739 \pm 0.019^{b} \\
(-24.59 \%)\end{array}$ \\
\hline
\end{tabular}

Data were displayed as mean \pm SE $(n=8)$. ${ }^{\text {a }}$ Significant difference at $\mathrm{P}>0.05$ as compared to control group, ${ }^{b S}$ Significant difference at $\mathrm{P}>0.05$ as compared to obese group. M. alba: Morus alba, SE: Standard error

Table 2: Effect of M. alba ethanolic extract on lipid profile in obese rats

\begin{tabular}{|c|c|c|c|c|}
\hline \multirow[t]{2}{*}{ Groups } & \multicolumn{4}{|l|}{ Parameters } \\
\hline & $\begin{array}{l}\text { Cholesterol } \\
\text { (mg/dL) }\end{array}$ & $\begin{array}{l}\text { Triglycerides } \\
\text { (mg/dL) }\end{array}$ & $\begin{array}{l}\text { HDL } \\
\text { (mg/dL) }\end{array}$ & $\begin{array}{l}\text { LDL } \\
\text { (mg/dL) }\end{array}$ \\
\hline $\begin{array}{l}\text { Control } \\
\text { group }\end{array}$ & $49.56 \pm 2.02$ & $49.65 \pm 1.71$ & $35.29 \pm 1.82$ & $13.42 \pm 0.94$ \\
\hline $\begin{array}{l}\text { Obese } \\
\text { group } \\
\text { (Ob) }\end{array}$ & $\begin{array}{l}101.19 \pm 1.75^{a} \\
(104.18 \%)\end{array}$ & $\begin{array}{l}79.18 \pm 2.32^{\mathrm{a}} \\
(37.29 \%)\end{array}$ & $\begin{array}{l}18.62 \pm 0.82^{a} \\
(-47.24 \%)\end{array}$ & $\begin{array}{l}25.52 \pm 0.91^{\mathrm{a}} \\
(90.16 \%)\end{array}$ \\
\hline $\begin{array}{l}\text { Ob+ } \\
\text { M. alba }\end{array}$ & $\begin{array}{l}72.20 \pm 2.81^{\mathrm{bc}} \\
(-28.65 \%)\end{array}$ & $\begin{array}{l}62.41 \pm 0.68^{\text {bc }} \\
(-21.18 \%)\end{array}$ & $\begin{array}{l}29.75 \pm 0.79^{b} \\
(59.77 \%)\end{array}$ & $\begin{array}{l}19.20 \pm 0.33^{\text {bc }} \\
(-24.76 \%)\end{array}$ \\
\hline $\mathrm{Ob}+\mathrm{Sim}$ & $\begin{array}{l}61.92 \pm 1.86^{b} \\
(-38.81 \%)\end{array}$ & $\begin{array}{l}53.42 \pm 2.31^{b} \\
(-32.53 \%)\end{array}$ & $\begin{array}{l}31.13 \pm 1.24^{b} \\
(67.19 \%)\end{array}$ & $\begin{array}{l}15.81 \pm 0.84^{\mathrm{b}} \\
(-38.05 \%)\end{array}$ \\
\hline
\end{tabular}

Data were exemplified as mean \pm SE of $(n=8)$. a Significant difference at $P>0.05$ as compared to control group, ${ }^{\mathrm{b} S i g n i f i c a n t}$ difference at $\mathrm{P}>0.05$ as compared to obese group, 'Significant difference at $\mathrm{P}>0.05$ as compared to simvastatin group. SE: Standard error, M. alba: Morus alba levels versus obese group. In contrast, a significant elevation in serum HDL level was demonstrated $(\mathrm{p}<0.05)$ in obese group received M. alba ethanolic extract $(59.77 \%)$ or simvastatin $(67.19 \%)$. It is worth mentioning that obese group administered $M$. alba ethanolic extract indicated a significant increment $(\mathrm{p}<0.05)$ in serum cholesterol, $\mathrm{LDL}$, and triglycerides levels versus obese group administered simvastatin. However, serum HDL level recorded no significant change $(p>0.05)$ in obese group received $M$. alba ethanolic extract as compared to obese group received simvastatin (Table 2).

Data in Table 3 revealed that serum glucose, insulin levels, and insulin resistant value were significantly enhanced $(\mathrm{p}<0.05)$ in obese group (152.64\%, 49.06\%, and $275.21 \%$, respectively) versus control group. However, M. alba ethanolic extract or simvastatin administration resulted in significant reduction $(\mathrm{p}<0.05)$ in serum glucose level $(-51.80 \%$ and $-53.32 \%$, respectively), insulin $(-11.00 \%$ and $-18.90 \%$, respectively), and insulin resistant $(-57.05 \%$ and $-62.11 \%$, respectively) values versus obese group. Interestingly, no significant alteration was detected $(\mathrm{p}>0.05)$ in serum glucose, insulin levels, and insulin resistant value between $M$. alba ethanolic extract and simvastatin-treated obese groups (Table 3).

Our findings in Table 4 represent the effect of $M$. alba ethanolic extract treatment on hepatic pro-oxidants content of obese rats. Where hepatic MDA and NO contents displayed significant elevation $(p<0.05)$ in obese group ( $476.05 \%$ and $672.37 \%$, respectively) versus control group. However, M. alba ethanolic extract or simvastatin-treated groups showed significant attenuation $(\mathrm{p}<0.05)$ in hepatic MDA $(-68.35 \%$ and $-73.85 \%$, respectively) and NO (-64.41\% and $-76.37 \%$, respectively) versus obese group (Table 4$)$. Noticeable, no marked change $(p>0.05)$ in

Table 3: Effect of M. alba ethanolic extract on serum glucose, insulin levels, and insulin resistant value in obese rats

\begin{tabular}{llll}
\hline Groups & Parameters & \\
\cline { 2 - 4 } & $\begin{array}{l}\text { Glucose } \\
(\mathbf{m g} / \mathbf{d L})\end{array}$ & $\begin{array}{l}\text { Insulin } \\
(\boldsymbol{\mu} \mathbf{I U} / \mathbf{m L})\end{array}$ & $\begin{array}{l}\text { Insulin } \\
\text { resistant } \\
(\mathbf{m g} / \mathbf{d L} \cdot \boldsymbol{\mu} \mathbf{I U} / \mathbf{m L})\end{array}$ \\
\hline Control group & $40.01 \pm 0.899$ & $12.21 \pm 0.39$ & $1.21 \pm 0.06$ \\
Obese group & $101.08 \pm 1.01^{\mathrm{a}}$ & $18.20 \pm 0.32^{\mathrm{a}}$ & $4.54 \pm 0.05^{\mathrm{a}}$ \\
(Ob) & $(152.64 \%)$ & $(49.06 \%)$ & $(275.21 \%)$ \\
Ob+M. alba & $48.72 \pm 1.70^{\mathrm{b}}$ & $16.22 \pm 0.19^{\mathrm{b}}$ & $1.95 \pm 0.02^{\mathrm{b}}$ \\
& $(-51.80 \%)$ & $(-11.00 \%)$ & $(-57.05 \%)$ \\
Ob+Sim & $47.18 \pm 2.43^{\mathrm{b}}$ & $14.76 \pm 0.32^{\mathrm{b}}$ & $1.72 \pm 0.04^{\mathrm{b}}$ \\
& $(-53.32 \%)$ & $(-18.90 \%)$ & $(-62.11 \%)$ \\
\hline
\end{tabular}

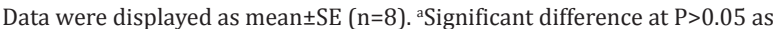

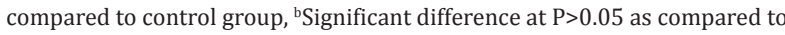
obese group. M. alba: Morus alba, SE: Standard error

Table 4: Effect of M. alba ethanolic extract on hepatic MDA and NO contents in obese rats

\begin{tabular}{lll}
\hline Groups & Parameters & \\
\cline { 2 - 3 } & $\begin{array}{l}\text { MDA (nmol/mg } \\
\text { protein) }\end{array}$ & $\begin{array}{l}\text { NO ( } \boldsymbol{\mu m o l} / \mathbf{m g} \\
\text { protein) }\end{array}$ \\
\hline Control group & $17.62 \pm 2.35$ & $5.61 \pm 0.28$ \\
Obese group (Ob) & $101.50 \pm 9.14^{\mathrm{a}}$ & $43.33 \pm 5.84^{\mathrm{a}}$ \\
& $(476.05 \%)$ & $(672.37 \%)$ \\
Ob+M. alba & $32.12 \pm 4.22^{\mathrm{bc}}$ & $15.42 \pm 2.13^{\mathrm{bc}}$ \\
& $(-68.35 \%)$ & $(-64.41 \%)$ \\
Ob+Sim & $(21.02 \%)$ & $(50.59 \%)$ \\
& $26.54 \pm 3.21^{\mathrm{b}}$ & $10.24 \pm 1.06^{\mathrm{b}}$ \\
& $(-73.85 \%)$ & $(-76.37 \%)$ \\
\hline
\end{tabular}

Data were displayed as mean $\pm \mathrm{SE}(\mathrm{n}=8)$. ${ }^{\text {Significant difference at } \mathrm{P}>0.05 \text { as }}$ compared to control group, bignificant difference at $\mathrm{P}>0.05$ as compared to obese group, 'Significant difference at $\mathrm{P}>0.05$ as compared to simvastatin group. M. alba: Morus alba, SE: Standard error 
hepatic MDA content between M. alba ethanolic extract and simvastatintreated obese groups. However, hepatic NO content demonstrated significant elevation $(\mathrm{p}<0.05)$ in $M$. alba ethanolic extract-treated obese group as compared to simvastatin-treated obese group (Table 4).

Results in Table 5 demonstrated liver functions recorded in obese rats after $M$. alba ethanolic extract administration. Where serum ALT (47.62\%), AST (51.34\%) activities as well as serum bilirubin (277.68\%) level were significantly increased $(\mathrm{p}<0.05)$ in obese rats versus control group. On the other hand, obese groups treated with $M$. alba ethanolic extract or simvastatin delivered marked reduction $(\mathrm{p}<0.05)$ serum ALT $(-15.89 \%$ and $-24.89 \%$, respectively), AST $(-27.14 \%$ and $-31.51 \%$, respectively) activities, and serum bilirubin $(-68.56 \%$ and $-71.87 \%$, respectively) level as compared to obese group. Of note, $M$. alba ethanolic extract-treated obese group indicated significant upregulation $(\mathrm{p}<0.05)$ in serum ALT activity and bilirubin level when compared to simvastatintreated obese group. Meanwhile, serum AST activity did not differ significantly ( $p>0.05$ ) in obese group received $M$. alba ethanolic extract from obese group received simvastatin (Table 5).

\section{Histopathological investigation}

Fig. 1 illustrated photomicrograph of liver tissue section of rat in the control group showing no histopathological alteration observed in the central vein and surrounding hepatocytes. Fig. 2 represented photomicrograph of liver tissue section of rat in the obese group showing ballooning degeneration in the hepatocytes associated with inflammatory cells infiltration in the portal area. Fig. 3 illustrated photomicrograph of liver tissue section of rat in obese group treated with ethanolic extract of M. alba showing dilatation and congestion in the central vein. Fig. 4 represented photomicrograph of liver tissue section of rat in the obese group treated with simvastatin demonstrating that the central and portal veins were dilated and congested.

\section{DISCUSSION}

Obesity is a chronic inflammatory disease recognized by elevated body weight and deposition of adipose tissue with extravagant fat storage [30]. Bioactive components from nature were indicated by many studies to possess a potential useful effect in treating obesity [31,32].

The current study went for investigating the possible effect of $M$. alba ethanolic extract in mitigating obesity-related hepatic steatosis and metabolic disorder represented by dyslipidemia, hyperinsulinemia, and glycemic status in obese rats.

Regarding anthropometric parameters, the present data revealed marked increment in the TC as well as AC in the obese group. Furthermore, BMI was significantly elevated in obese group with respect to control group. These results are in harmony with the data reported by Novelli et al. [13] who found fat aggregation in the thoracic and abdominal locales after feeding rats with HCD. Thus,

Table 5: Effect of M. alba ethanolic extract on liver functions in obese rats

\begin{tabular}{llll}
\hline Groups & \multicolumn{2}{l}{ Parameters } & \\
\cline { 2 - 4 } & ALT (U/L) & AST (U/L) & $\begin{array}{l}\text { Bilirubin } \\
\text { (mg/dL) }\end{array}$ \\
\hline Control group & $125.82 \pm 5.52$ & $320.81 \pm 8.21$ & $1.12 \pm 0.05$ \\
Obese & $185.74 \pm 7.26^{\mathrm{a}}$ & $485.51 \pm 9.27^{\mathrm{a}}$ & $4.23 \pm 0.60^{\mathrm{a}}$ \\
group (Ob) & $(47.62 \%)$ & $(51.34 \%)$ & $(277.68 \%)$ \\
Ob+M. alba & $156.21 \pm 3.48^{\mathrm{b}}$ & $353.75 \pm 6.54^{\mathrm{b}}$ & $1.33 \pm 0.07^{\mathrm{b}}$ \\
& $(-15.89 \%)$ & $(-27.14 \%)$ & $(-68.56 \%)$ \\
& $(11.98 \%)$ & $(5.99 \%)$ & $(11.76 \%)$ \\
Ob+Sim & $139.50 \pm 4.11^{\mathrm{b}}$ & $332.53 \pm 5.68^{\mathrm{b}}$ & $1.19 \pm 0.05^{\mathrm{b}}$ \\
& $(-24.89 \%)$ & $(-31.51 \%)$ & $(-71.87 \%)$ \\
\hline
\end{tabular}

Data were exemplified as mean $\pm \mathrm{SE}(\mathrm{n}=8)$. ${ }^{\text {SSignificant difference at } \mathrm{P}>0.05 \text { as }}$

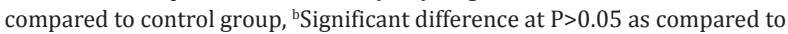
obese group. M. alba: Morus alba, SE: Standard error the recorded increment in body weight could be attributed to the accumulation of adipose tissue and excessive energy intake. BMI has been expressed to be a reliable indicator of body fat and obesity in rats [13]. As daily lipid intake, BMI and fat deposition are positively correlated [33].

Treating obese rats with $M$. alba ethanolic extract or simvastatin (antihypercholesterolemic drug) resulted in significant reduction in $\mathrm{TC}, \mathrm{AC}$, and $\mathrm{BMI}$ as compared to obese group. The recorded drop in these anthropometric parameters upon treatment with M. alba ethanolic extract could be explained by its ability to decrease body fat proportion in obese rats. This effect could be attributed to the capability of active ingredients of M. alba, namely, mulberroside A, 5,7,2V-trihydroxyflavanone-4V-O-h-dglucoside and albanols A and B to suppress sterol regulatory component binding protein 1 release with subsequent inhibition in lipid aggregation and lipogenic genes expression, leading to a reduction in body lipids [34]. Moreover, M. alba contains cyanidin-3-glucoside, cyanidin-3-rutinoside, and pelargonidin3-glucoside which might be contributed to repress body weight gain [35]. Furthermore, M. alba has been found to ameliorate adipocytokine dysregulation and suppress macrophage infiltration, which are involved in the development of obesity [36]. These may be the conceivable mechanisms implicated in weight reduction, and BMI regulation observed after M. alba ethanolic extract administration in obese rats.

The recorded alleviation in the anthropometric parameters in simvastatin-treated obese group might be explained by alteration in

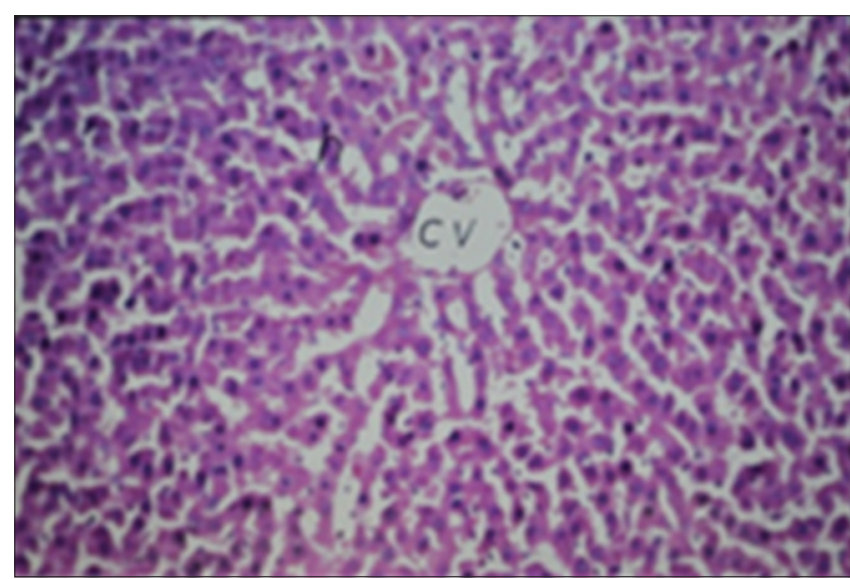

Fig. 1: Photomicrograph of liver tissue section of rat in the control group showing normal histological architecture of the central vein and surrounding hepatic cells ( $H$ and $E, \times 40)$

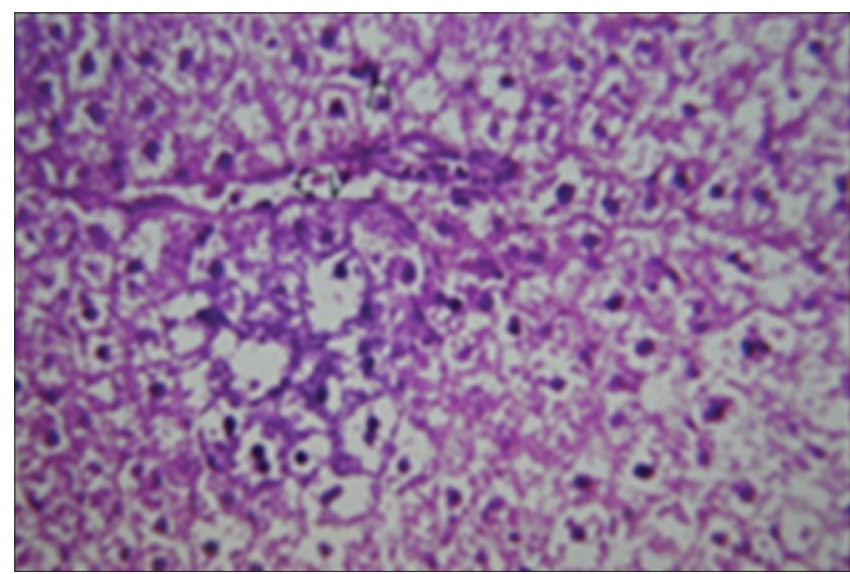

Fig. 2: Photomicrograph of obese group liver tissue showing ballooning degeneration in the hepatic cells and infiltrating inflammatory cells in the portal region $(\mathrm{H}$ and $\mathrm{E}, \times 40)$ 
adiponectin levels independent of adiposity induced by simvastatin supplementation [37]. Simvastatin affects atherogenic lipoproteins as well as reduces both LDL and triglyceride-rich lipoproteins, which forms non-HDL cholesterol. Moreover, a reduction in non-HDL cholesterol associated with an elevation in HDL cholesterol levels has been observed after administration of a higher dose of simvastatin [38].

The present results showed marked increment in serum cholesterol triglycerides, and LDL levels associated with a significant drop in serum HDL level in obese rats regarding the control group. These data are in the same line with the previous findings of Son et al. [39] who reported significant elevation in cholesterol and triglycerides in obese rats. Furthermore, Fruchart et al. [40] stated that adipose tissue lipids are derived to a great extent from triglycerides particularly during elevated cholesterol diet intake. In addition, high cholesterol supplementation resulted in enhanced serum LDL level in obese rats [13]. This finding was clarified by the suppressed HDL level, as detected in our study, by suppressing the reverse cholesterol transport from circulatory system to the liver [41]. Moreover, elevated cholesterol diet causes oxidative stress prompting that generates reactive oxygen species (ROS), which causes cellular damage via oxidation of membrane lipids, proteins, and DNA of the cell. Thus, increased level of blood cholesterol particularly LDL is considered a major hazard for cholesterol-rich diet [42].

Most international and national lipid management protocols consider LDL cholesterol as a primary target of hypolipidemic therapy. M. alba ethanolic extract or simvastatin, used in the current study as therapeutic

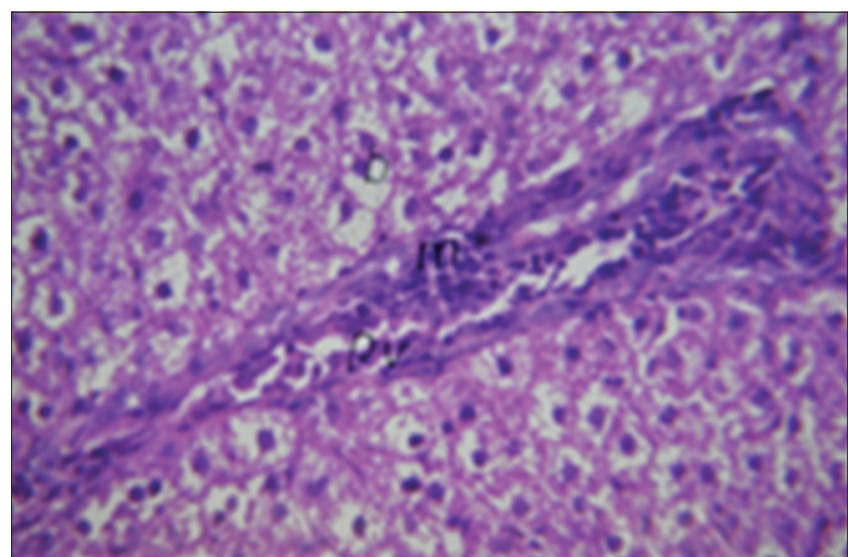

Fig. 3: Photomicrograph liver tissue of M. alba ethanolic extracttreated obese group showing dilatation and congestion in the central vein $(H$ and $E, \times 40)$.

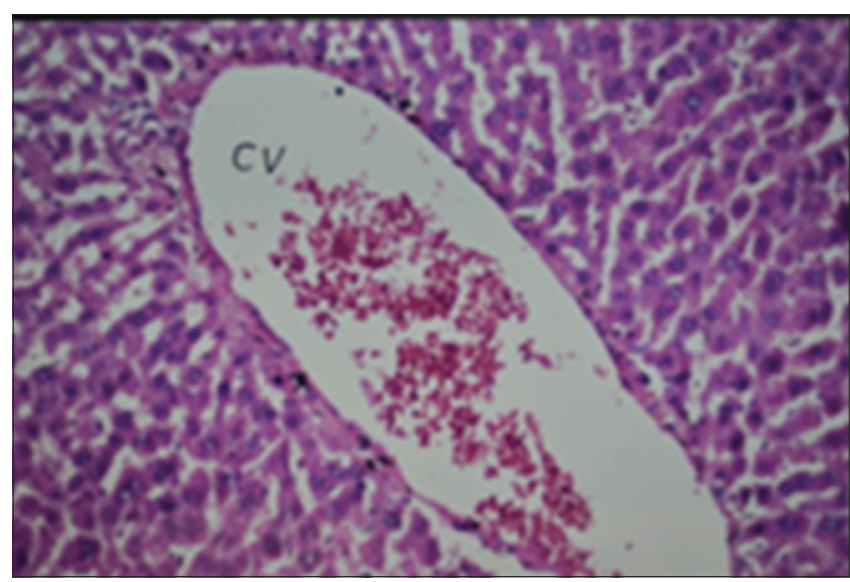

Fig. 4: Photomicrograph of liver tissue simvastatin-treated obese group showing that the central and portal veins were dilated and congested $(\mathrm{H}$ and $\mathrm{E}, \times 40)$ candidates could attenuate serum cholesterol, triglycerides, and LDL levels, whereas elevated serum HDL level relative to obese group. In accordance with our results, Lee et al. [43] indicated that $M$. alba could regulate energy balance and prevent metabolic disorders via regulation of lipid metabolism particularly triglycerides and cholesterol metabolism in obese mice. In addition, M. alba contains $24.3 \%$ dietary fiber, known to suppress triglycerides levels by inhibiting hepatic lipogenesis. It also reduces plasma LDL cholesterol by hindering the absorption of cholesterol and bile acid and enhancing LDL-receptor activity [44].

Treatment with simvastatin, in the present study, could ameliorate lipid profile by reducing serum cholesterol, triglycerides, and LDL levels and increasing HDL level versus obese group. Our results are in agreement with the previous reports [45,46]. Simvastatin belongs to inhibitors of 3-hydroxy-3-methylglutaryl coenzyme A reductase, a lipid lowering drug. Sabri et al. [47] demonstrated that simvastatin significantly reduced oxidative stress that contributes to obesity progression. It could significantly inhibit the induction of oxygen radicals subsequently, diminishes oxidative stress, increases HDL level, and improves lipid profile [48].

The present results demonstrated that obese group exhibited significant upregulation in serum glucose level relative to the control group. This result is in consonance with an earlier report of Galisteo et al. [49]. This finding could be attributed to enhanced lipolytic activity during fat aggregation causing high free unsaturated fats mobilization to the liver. Raised unsaturated fats flux to the liver enhances gluconeogenesis and diminishes the impact of insulin on peripheral glucose disposal [50].

The current results indicated that there was a significant decline in glucose serum level in the obese group treated with M. alba ethanolic extract versus obese group. Cyanidin-3-glucoside and cyanidin-3rutinoside in $M$. alba could suppress body weight gain and body fat. Moreover, these active ingredients could decrease serum leptin levels and improve $\beta$ cell function [35]. Furthermore, 1-deoxynojirimycin (DNJ), an active compound in mulberry leaves, has been reported to restrain intestinal $\alpha$-glucosidases, which suppresses the absorption of glucose from the intestine [51]. More recently, it was found that the hybrid of DNJ and polysaccharide from mulberry leaves had antidiabetic effect via regulating the hepatic gluconeogenesis enzymes, glucokinase, phosphoenolpyruvate carboxykinase, and glucose-6-phosphatase expression [52].

Supplementation of obese group with simvastatin resulted in significant reduction in serum glucose level relative to obese group. Simvastatin has been found to suppress elevation of intracellular $\mathrm{Ca}^{+2}$ level induced by glucose in a dose-dependent way. Furthermore, simvastatin could inhibit glucose-induced insulin secretion from islets [53].

Our results recorded a significant elevation in serum insulin level and insulin resistance in obese group versus control group. These findings come in accordance with those of Galisteo et al. [49]. This could be attributed to the correlation between obesity and chronic systemic inflammation which conceivably prompts insulin resistance [54].

Obese group supplemented with M. alba ethanolic extract showed a significant decline in serum insulin level and insulin resistance value as compared to obese group alone. These effects of $M$. alba extract may be due to the powerful anti-inflammatory action of its major constituents (prenylated flavonoid) [55]. This property inhibited pro-inflammatory cytokine production and enhanced anti-inflammatory mediators. Thus, M. alba ethanolic extract could suppress hyperinsulinemia in obese rats.

Results of the current study revealed a significant decrement in insulin level and insulin resistance value in the serum of simvastatin-treated obese rats as compared to obese group. Simvastatin possesses antiinflammatory capacity as it could inhibit the expression of oxLDLinduced mRNA and the production of tumor necrosis factor- $\alpha$ (TNF- $\alpha$ ) 
and monocyte chemoattractant protein-1 [35]. In addition, simvastatin exerted anti-inflammatory action in adipose tissue via inhibition of endoplasmic reticulum stress. Suppression of endoplasmic reticulum stress in adipocytes represented an alternative mechanism of the pleiotropic action of statins.

The present study confirmed that lipid peroxidation, a downstream chain reaction initiated by free radicals, was activated as reflected by the increased level of lipid peroxidation product, MDA in the liver of obese group when compared with control group. This outcome is in conformity with that of Prasanna and Purnima [56]. Increased caloric intake results in a marked decline in mitochondrial fluidity and promotes ROS generation which in turn increases the hepatic content of MDA in obese rats [57]. Furthermore, the investigation of Novelli et al. [13] illustrated that BMI is positively correlated to lipid peroxides product concentration.

The significant decline in hepatic MDA content recorded in the obese group treated with M. alba extract versus obese group could be credited to the presence of rutin which is considered to be the most abundant phenolic compound in mulberry [58]. It is well known that phenolic compounds have powerful antioxidant activity. They have a strong ability to restrain lipid peroxidation via chain-breaking superoxide anion radical scavengers [59]. Thus, protecting LDL from oxidation [60].

The present results indicated significant suppression in hepatic MDA content in simvastatin-treated obese group in comparison with obese group. This effect could be due to its hypolipidemic effect and antioxidant potential [61]. Sabri et al. [47] showed that simvastatin could notably diminish oxidative stress, which is a contributory agent for obesity, by means of restraining the generation of oxygen radicals independent of its cholesterol lowering effects.

NO indicated significant elevation in liver tissues of obese groups versus the control group. Choi et al. [62] stated that NO generation increases in obese and not in healthy participants. NO is a free radical known to be included in the regulation of many physiological and pathophysiological procedures, for example, vasodilatation, energy balance, and inflammatory reactions [63,64]. NO synthase (NOS) regulates the synthesis of NO. NOS are three isoforms: Endothelial NOS (eNOS), neuronal NOS, and inducible NOS (iNOS) [63]. eNOS isoform promotes the generation NO in small amounts with vasodilatator and antiatherosclerotic capacity. In morbidly obese (MO) patients, the expression of eNOS is downregulated boosting endothelial dysfunction. iNOS expression is upregulated in MO patients by elevated concentration of tumor TNF- $\alpha$ and it induces vascular and pancreatic beta cells damage, enhancing obesity-associated metabolic disorder [63,64]. Chronic inflammation and oxidative stress represent key features of obesity and are strongly related to each other $[65,66]$. Inflammatory cytokines elevated in MO patients mediate upregulation of iNOs isoform which induces NO generation at 1000-folds more than eNOs. [67].

The present results demonstrated a significant decrease in NO content in the liver of obese rats received M. alba ethanolic extract versus obese group. This result is in keeping with the recent investigation of Eo et al. [68] who reported that M. alba could block NO production via suppressing iNOS overexpression. Furthermore, the previous study conducted by Choi and Hwang [69], revealed that methanolic extract from M. alba leaves and its subfractions (chloroform, butanol, and aqueous fractions) restrains NO generation and significantly declines TNF- $\alpha$ release in LPS activated RAW264.7 macrophages.

Supplementation of obese group with simvastatin resulted in significant reduction in NO content in the liver relative to obese group. Simvastatin was found to suppress iNOS expression and prevent the generation of excess NO and nitrosative tissue stress [70]. More recent study mentioned that simvastatin could block nuclear factor-кB signaling pathway activation which promotes TNF- $\alpha$ and iNOS genes transcription [71].
The significant increment in serum AST, ALT activity, and bilirubin level represents a clinical indicator for liver tissue damage caused by toxicants or disease conditions [72]. In obese group, the activity of liver enzymes (AST and ALT) in serum as well as serum bilirubin level was significantly elevated relative to those in the control group. The quantity of the released cellular enzymes detected in the blood indicates the change in plasma membrane integrity and/or hepatocytes permeability. Obesity is known to produce oxidative stress and promotes the generation of ROS, which leads to overproduction of peroxidized lipid molecule in liver tissue as indicated by enhanced MDA content in the liver. Overproduction of lipid peroxides causes destabilization in cellular lipid substances inducing oxidative damage, especially of membrane structures. This leads to the leakage of liver enzymes into the circulation. Moreover, lipid peroxidation products and NO overproduction can trigger the excitotoxic process causing an imbalance in cellular functions as indicated by the increased serum level of bilirubin in obese rats [57].

M. alba ethanolic extract-treated obese group exhibited marked improvement in liver functions as evident from the significantly blunted activity of liver enzymes in serum and the significant drop of serum bilirubin level in the treated rats relative to obese counterparts. The therapeutic effects of most medicinal plants are attributed to their antioxidant properties which in turn, could be ascribed to their antioxidant phytochemicals. The hepatoprotective effect of $M$. alba extract could be mainly due to its antioxidant and free radical scavenging properties of its active constituents which have been demonstrated in various studies [73]. Thus, this effect of $M$. alba extract confirms the ability of its active ingredients to maintain the architectural integrity of hepatocytes and in turn, restrict the leakage of liver enzymes into circulation. This indicates the membrane-stabilizing property of M. alba extract.

Administration of simvastatin in obese rats markedly reduced serum activity of liver enzymes as well as the serum level of bilirubin versus obese rats. Abbas and Sakr [74] reported that the protective effect of simvastatin on the liver was established by the significant reduction of oxidative stress and alleviation of liver functions. These findings are in accordance with the reported results of Cui et al. [75] who illustrated downregulation of liver enzymes in the serum of HFD-fed rats treated with simvastatin.

In the present study, the histopathological investigation of liver tissue specimens in obese rats showed ballooning degeneration (cytoplasmic vacuolization) in the hepatocytes (hepatic steatosis) linked with inflammatory cells infiltration in the portal zone. These findings are in agreement with those of Abbas and Sakr [74] who reported that the detection of oxidative damage in the liver of rats kept on highfat diet for 15 weeks was indicated by changes in oxidative stress markers as well as by histopathological investigation that revealed cytoplasmic vacuolization, degeneration, necrosis, and fatty alteration of hepatocytes which confirmed that the cells were severely injured.

Here, in the favorable impact of the treatment with M. alba ethanolic extract on liver tissue was manifested by the remarkable amendment in the cell integrity as showed in the histopathological examination. This indicates that M. alba ethanolic extract could restore the structural organization of the liver. This effect could be attributed to the antioxidant effect of the mulberry constituents [34]. The leaf of mulberry contains triterpenes (lupeol), sterols ( $\beta$-sitosterol), bioflavonoids (rutin, moracetin, quercetin-3-triglucoside, and isoquercitrin), coumarins, volatile oil, alkaloids, amino acids, and organic acids [76], which are considered to be valuable in inhibiting inflammatory and oxidative stress. Therefore, M. alba is considered as a major protector for cells against oxidative stress [77].

Administration of simvastatin in obese rats significantly improves hepatocyte degeneration as showed in the histopathological finding. This result is in line with the previously reported finding of Abbas and 
Sakr [74] who demonstrated the improvement of liver tissue structure upon treatment of rats with simvastatin. This event could be explained by the hepatoprotective and antioxidant potential of simvastatin Cui et al. [75].

\section{CONCLUSION}

From the present experimental setting, it seems that successful obesity treatment will likely require intervention therapy that targets multiple systems. M. alba ethanolic extract imparted hypolipidemic effect, antiinflammatory action, and antioxidative activity in mitigating obesityinduced hepatic steatosis and related aspects of metabolic disorder in the experimental model of obesity.

\section{REFERENCES}

1. Himaja N, Shama NS. Herbal wealth for hepatotoxicity: A review. Asian J Pharm Clin Res 2015;8(1):3-9.

2. Wolf PL. Biochemical diagnosis of liver disease. Indian J Clin Biochem 1999;14(1):59-90.

3. Piyachaturawat $P$, Chai-ngam N, Chuncharunee A, Komaratat $P$, Suksamrarn A. Choleretic activity of phloracetophenone in rats: Structure-function studies using acetophenone analogues. Eur J Pharmacol 2000;387(2):221-7.

4. Ward FM, Daly MJ. Hepatic disease. In: Clinical Pharmacy and Therapeutics. Churchill Livingstone; 1999. p. 195-212.

5. Ahmed HH, Hamza AH, Kotob SE. Corn silk offers multimechanistic approaches in mitigating obesity in rodents. Asian J Pharm Clin Res 2016;9(4):1-7.

6. Trayhurn P, Beattie JH. Physiological role of adipose tissue: White adipose tissue as an endocrine and secretory organ. Proc Nutr Soc 2001;60(3):329-39.

7. Xu H, Barnes GT, Yang Q, Tan G, Yang D, Chou CJ, et al. Chronic inflammation in fat plays a crucial role in the development of obesityrelated insulin resistance. J Clin Invest 2003;112(2):1821-30.

8. Trayhurn P, Wood IS. Adipokines: Inflammation and the pleiotropic role of white adipose tissue. Br J Nutr 2004;92(3):347-55.

9. Diehl AM, Li ZP, Lin HZ, Yang SQ. Cytokines and the pathogenesis of non-alcoholic steatohepatitis. Gut 2005;54:303-6.

10. Chen J, Li X. Hypolipidemic effect of flavonoids from mulberry leaves in triton WR-1339 induced hyperlipidemic mice. Asia Pac J Clin Nutr 2007;16 Suppl 1:290-4.

11. Butt MS, Nazir A, Sultan MT, Schroën K. Morus alba L. Nature's functional tonic. Trends Food Sci Technol 2008;19:505-12.

12. Soliman MM, Attia HF, El-Shazly SA, Saleh OM. Biomedical effects of cinnamon extract on obesity and diabetes relevance in wistar rats. Am J Biochem Mol Biol 2012;2:133-45.

13. Novelli EL, Diniz YS, Galhardi CM, Ebaid GM, Rodrigues HG, Mani F, et al. Anthropometrical parameters and markers of obesity in rats. Lab Anim 2007;41(1):111-9.

14. Sarikaphuti A, Nararatwanchai T, Hashiguchi T, Ito T, Thaworanunta S, Kikuchi K, et al. Preventive effects of Morus alba L. anthocyanins on diabetes in Zucker diabetic fatty rats. Exp Ther Med 2013;6(3):689-95.

15. Mbikay M. Therapeutic potential of Moringa oleifera leaves in chronic hyperglycemia and dyslipidemia: A review. Front Pharmacol 2012;3:24.

16. Meiattini F, Prencipe L, Bardelli F, Giannini G, Tarli P. The 4-hydroxybenzoate/4-aminophenazone chromogenic system used in the enzymic determination of serum cholesterol. Clin Chem 1978;24(12):2161-5.

17. Bucolo G, David H. Quantitative determination of serum triglycerides by the use of enzymes. Clin Chem 1973;19(5):476-82.

18. Naito HK. HDL cholesterol. In: Kaplan A, editor. Clinical Chemistry: Theory, Analysis and Correlation. St. Louis, Toronto, Princeton: C.V. Mosby Co.; 1984. p. 1207-13, 437.

19. Trinder P. Determination of glucose in blood using glucose oxidase with an alternative oxygen acceptor. Ann Clin Biochem 1969;6:24-33.

20. Wieland H, Seidel D. A simple specific method for precipitation of low density lipoproteins. J Lipid Res 1983;24(7):904-9.

21. Eastham RD. Biochemical Values in Clinical Medicine. $7^{\text {th }}$ ed. Bristol England: John Wright \& Sons Ltd.; 1985.

22. Satoh K. Serum lipid peroxide in cerebrovascular disorders determined by a new colorimetric method. Clin Chim Acta 1978;90:37-43.

23. Montgoery HA, Dymock JF. The determination of nitrate in water. Analyst 1961;86:414.

24. Young DS. Effect of Drugs on Clinical Laboratory Tests. $3^{\text {rd }}$ ed., Vol. 3. Washington, DC: AACC Press; 1990. p. 6-12.
25. Walterv M, Gerade H. A colorimetric method for determination bilirubin in serum and plasma. Microchem J 1970;15:231.

26. Lowry OH, Rosebrough NJ, Farr AL, Randall RJ. Protein measurement with the Folin phenol reagent. J Biol Chem 1951;193(1):265-75.

27. Matthews DR, Hosker JP, Rudenski AS, Naylor BA, Treacher DF, Turner RC. Homeostasis model assessment: Insulin resistance and betacell function from fasting plasma glucose and insulin concentrations in man. Diabetologia 1985;28(7):412-9.

28. Banchroft JD, Stevens A, Turner DR. Theory and Practice of Histological Techniques. $4^{\text {th }}$ ed. New York, London, San Francisco, Tokyo: Churchil Livingstone; 1996.

29. Abramoff MD, Magalhaes PJ, Ram SJ. Image processing with image J Biophotonics Int 2004;11(7):36-42.

30. Lee YH, Pratley RE. The evolving role of inflammation in obesity and the metabolic syndrome. Curr Diab Rep 2005;5(1):70-5.

31. Rayalam S, Della-Fera MA, Baile CA. Phytochemicals and regulation of the adipocyte life cycle. J Nutr Biochem 2008;19(11):717-26.

32. Thielecke F, Boschmann M. The potential role of green tea catechins in the prevention of the metabolic syndrome - A review. Phytochemistry 2009;70:11-24

33. Rodrigues A, Pereira PC, Vicente AF, Brito JA, Bernardo MA, Mesquita MF. Food intake, body mass index and body fat mass in elderly. Asian J Clin Nutr 2012;4:107-15.

34. El-Beshbishy HA, Singab AN, Sinkkonen J, Pihlaja K. Hypolipidemic and antioxidant effects of Morus alba L. (Egyptian mulberry) root bark fractions supplementation in cholesterol-fed rats. Life Sci 2006;78(23):2724-33.

35. Wu ZH, Chen YQ, Zhao SP. Simvastatin inhibits ox-LDL-induced inflammatory adipokines secretion via amelioration of ER stress in 3T3-L1 adipocyte. Biochem Biophys Res Commun 2013;432(2):365-9.

36. Sugimoto M, Arai H, Tamura Y, Murayama T, Khaengkhan P, Nishio T, et al. Mulberry leaf ameliorates the expression profile of adipocytokines by inhibiting oxidative stress in white adipose tissue in $\mathrm{db} / \mathrm{db}$ mice. Atherosclerosis 2009;204:388-94.

37. Koh KK, Quon MJ, Han SH, Lee Y, Kim, SJ, Park JP, et al. Differential metabolic effects of pravastatin and simvastatin in hypercholesterolemic patients. Atherosclerosis 2009;204(2):483-90.

38. Ballantyne CM, Olsson AG, Cook TJ, Mercuri MF, Pedersen TR, Kjekshus J. Influence of low high-density lipoprotein cholesterol and elevated triglyceride on coronary heart disease events and response to simvastatin therapy in 4S. Circulation 2001;104(25):3046-51.

39. Son EL, Pal UK, Mandal PK, Hong GE, Kim SK, Lee CH. Hypolipidaemic effect of processed sulfur, Allium tuberosum Rottl. and fermented Allium tuberosum Rottl in rat. Asian J Anim Vet Adv 2012; 7:812-21.

40. Fruchart JC, Brewer HB Jr, Leitersdorf E. Consensus for the use of fibrates in the treatment of dyslipoproteinemia and coronary heart disease. Fibrate Consensus Group. Am J Cardiol 1998;81:912-7.

41. Raveh O, Pinchuk I, Fainaru M, Lichtenberg D. Kinetics of lipid peroxidation in mixtures of HDL and LDL, mutual effects. Free Radic Biol Med 2001;31(11):1486-97.

42. Jain PG, Patil SD, Haswani NG, Girase MV, Surana SJ. Hypolipidemic activity of Moringa oleifera Lam., Moringaceae, on high fat diet induced hyperlipidemia in albino rats. Braz J Pharm 2010;20(6):969-73.

43. Lee J, Chae K, Ha J, Park BY, Lee HS, Jeong S, et al. Regulation of obesity and lipid disorders by herbal extracts from Morus alba, Melissa officinalis, and Artemisia capillaris in high-fat diet-induced obese mice. J Ethnopharmacol 2008;115(2):263-70.

44. Venkatesan N, Devaraj SN, Devaraj H. Increased binding of LDL and VLDL to apo B,E receptors of hepatic plasma membrane of rats treated with Fibernat. Eur J Nutr 2003;42(5):262-71.

45. Matikainen N, Kahri J, Taskinen MR. Reviewing statin therapy in diabetes - Towards the best practise. Prim Care Diabetes 2010;4(1):9-15.

46. Yao XM, Ye SD, Zai Z, Chen Y, Li XC, Yang GW, et al. Simvastatin protects diabetic rats against kidney injury through the suppression of renal matrix metalloproteinase-9 expression. J Endocrinol Invest 2010;33(2):292-6

47. Sabri M, Ai J, Marsden PA, Macdonald RL. Simvastatin re-couples dysfunctional endothelial nitric oxide synthase in experimental subarachnoid hemorrhage. PLoS One 2011;6(2):e17062.

48. Delbosc S, Cristol JP, Descomps B, Mimran A, Jover B. Simvastatin prevents angiotensin II-induced cardiac alteration and oxidative stress. Hypertension 2002;40(2):142-7.

49. Galisteo M, Sánchez M, Vera R, González M, Anguera A, Duarte J, et al. A diet supplemented with husks of Plantago ovata reduces the development of endothelial dysfunction, hypertension, and obesity by affecting adiponectin and TNF-alpha in obese Zucker rats. J Nutr 
2005;135(10):2399-404.

50. Ginsberg HN, Stalenhoef AF. The metabolic syndrome: Targeting dyslipidaemia to reduce coronary risk. J Cardiovasc Risk 2003;10(2):121-8.

51. Hansawasdi C, Kawabata J. Alpha-glucosidase inhibitory effect of mulberry (Morus alba) leaves on Caco-2. Fitoterapia 2006;77(7-8):568-73.

52. Li YG, Ji DF, Zhong S, Lv ZQ, Lin TB, Chen S. Hybrid of 1-deoxynojirimycin and polysaccharide from mulberry leaves treat diabetes mellitus by activating PDX-1/insulin-1 signaling pathway and regulating the expression of glucokinase, phosphoenolpyruvate carboxykinase and glucose-6-phosphatase in alloxan-induced diabetic mice. J Ethnopharmacol 2011;134(3):961-70.

53. Yada T, Nakata M, Shiraishi T, Kakei M. Inhibition by simvastatin, but not pravastatin, of glucose-induced cytosolic $\mathrm{Ca} 2$ signalling and insulin secretion due to blockade of L-type Ca2 channels in rat islet beta-cells. Br J Pharmacol 1999;126(5):1205-13.

54. Mori N, Lee P, Yamamoto I, Nozawa S, Arai T. Insulin treatmentinduced daily changes to plasma adiponectin and TNF- $\alpha$ level and lipid metabolism parameters in dogs suffering from type 1 diabetes mellitus Asian. J Anim Vet Adv 2011;6:844-50.

55. Lim HJ, Jin HG, Woo ER, Lee SK, Kim HP. The root barks of Morus alba and the flavonoid constituents inhibit airway inflammation. J Ethnopharmacol 2013;149(1):169-75.

56. Prasanna GS, Purnima A. Protective effect of leaf extract of Trichilia connaroides on hypercholesterolemia induced oxidative stress. Int $\mathrm{J}$ Pharmacol 2011;7:106-12.

57. Esposito LA, Melov S, Panov A, Cottrell BA, Wallace DC. Mitochondrial disease in mouse results in increased oxidative stress. Proc Natl Acad Sci U S A 1999;96:4820-5.

58. Radojkovic' MM, Zekovic' ZP, Vidovic' SS, Koc`ar DD, Maškovic' PZ. Free radical scavenging activity and total phenolic and flavonoid contents of mulberry (Morus spp. L., Moraceae) extracts. Hemijska Ind 2012;66:547-52.

59. Wang Y, Xiang L, Wang C, Thang C, He Y. Antidiabetic and antioxidant effects and phytochemicals of mulberry fruit (Morus alba L.) polyphenol enhanced extract. PLoS One 2013;8:e71144.

60. O'Byrne DJ, Devaraj S, Grundy SM, Jialal I. Comparison of the antioxidant effects of Concord grape juice flavonoids alpha-tocopherol on markers of oxidative stress in healthy adults. Am J Clin Nutr 2002;76(6):1367-74.

61. Heeba G, Moselhy ME, Hassan M, Khalifa M, Gryglewski R, Malinski T. Anti-atherogenic effect of statins: Role of nitric oxide, peroxynitrite and haem oxygenase-1. Br J Pharmacol 2009;156:1256-66.

62. Choi JW, Pai SH, Kim SK, Ito M, Park CS, Cha YN. Increases in nitric oxide concentrations correlate strongly with body fat in obese humans. Clin Chem 2001;47(6):1106-9.
63. Avogaro A, de Kreutzenberg SV. Mechanisms of endothelial dysfunction in obesity. Clin Chim Acta 2005;360(1-2):9-26.

64. Joost HG, Tschöp MH. NO to obesity: Does nitric oxide regulate fa oxidation and insulin sensitivity? Endocrinology 2007;148:4545-7.

65. Wang Z, Nakayama T. Inflammation, a link between obesity and cardiovascular disease. Mediators Inflamm 2010;2010:535918.

66. Fernández-Sánchez A, Madrigal-Santillán E, Bautista M, EsquivelSoto J, Morales-González A, Esquivel-Chirino C, et al. Inflammation, oxidative stress, and obesity. Int J Mol Sci 2011;12(5):3117-32.

67. Codoñer-Franch P, Tavárez-Alonso S, Murria-Estal R, Megías-Vericat J Tortajada-Girbés M, Alonso-Iglesias E. Nitric oxide production is increased in severely obese children and related to markers of oxidative stress and inflammation. Atherosclerosis 2011;215(2):475-80.

68. Eo HJ, Park JH, Park GH, Lee MH, Lee JR, Koo JS, et al. Antiinflammatory and anti-cancer activity of mulberry (Morus alba L.) root bark. BMC Complement Altern Med 2014;14:200.

69. Choi EM, Hwang JK. Effects of Morus alba leaf extract on the production of nitric oxide, prostaglandin E2 and cytokines in RAW264.7 macrophages. Fitoterapia 2005;76(7-8):608-13.

70. Iliodromitis EK, Andreadou I, Prokovas E, Zoga A, Farmakis D Fotopoulou T, et al. Simvastatin in contrast to postconditioning reduces infarct size in hyperlipidemic rabbits: Possible role of oxidative/nitrosative stress attenuation. Basic Res Cardiol 2010;105(2):193-203.

71. Piechota-Polanczyk A, Goraca A, Demyanets S, Mittlboeck M, Domenig C, Neumayer C, et al. Simvastatin decreases free radicals formation in the human abdominal aortic aneurysm wall via NF-?B. Eur J Vasc Endovasc Surg 2012;44(2):133-7.

72. Radi ZA, Koza-Taylor PH, Bell RR, Obert LA, Runnels HA, Beebe JS, et al. Increased serum enzyme levels associated with kupffer cell reduction with no signs of hepatic or skeletal muscle injury. Am J Pathol 2011;179:240-7.

73. Oh H, Ko EK, Jun JY, Oh MH, Park SU, Kang KH, et al. Hepatoprotective and free radical scavenging activities of prenylflavonoids, coumarin, and stilbene from Morus alba. Planta Med 2002;68(10):932-4.

74. Abbas AM, Sakr HF. Simvastatin and vitamin E effects on cardiac and hepatic oxidative stress in rats fed on high fat diet. J Physiol Biochem 2013;69(4):737-50

75. Cui B, Liu S, Lin X, Wang J, Li S, Wang Q, et al. Effects of Lycium barbarum aqueous and ethanol extracts on high-fat-diet induced oxidative stress in rat liver tissue. Molecules 2011;16(11):9116-28.

76. Doi K, Kojima T, Makino M, Kimura Y, Fujimoto Y. Studies on the constituents of the leaves of Morus alba L. Chem Pharm Bull (Tokyo) 2001;49(2):151-3.

77. Ou TT, Kuo CY, Chyau CC, Lee HJ, Peng JS, Wang CJ. Improvement of lipopolysaccharide-induced hepatic injuries and inflammation with mulberry extracts. J Sci Food Agric 2013;93(8):1880-6. 